\title{
Expanding the definition of covid-19 deaths will show the true effect of the pandemic
}

\author{
Peter L Labib surgical registrar, Somaiah Aroori consultant hepatopancreaticobiliary surgeon \\ University Hospitals Plymouth NHS Trust, Derriford Hospital, Plymouth PL6 8DH, UK
}

Appleby asks what is happening to non-covid deaths. ${ }^{1}$ The covid-19 pandemic has significantly affected our hepatopancreaticobiliary unit. Because of the need to ring fence critical care facilities, our theatre lists have been reduced, and surgery is only proceeding in cases likely to become inoperable before normal service resumes. Unfortunately, many patients will develop inoperable disease before theatre capacity is reinstated. Although many patients would have developed postoperative cancer recurrence, several would have been cured of their disease had they undergone surgery more promptly. Access to palliative chemotherapy for patients with inoperable disease has also been severely restricted. Life expectancy in these patients will be substantially reduced if they do not have access to locoregional or systemic treatments for their cancer.

Mortality statistics for covid-19 capture patients who die as a direct result of coronavirus infection but not patients who die indirectly as a result of the pandemic. To better capture the true mortality, including additional and premature deaths secondary to affected clinical services, we suggest the following classification:

Primary death: patients who died from covid-19 infection

Secondary death: patients with potentially curable diseases who died owing to a lack of access to medical interventions
Tertiary death: patients with incurable diseases who died earlier than would be expected owing to a lack of access to medical interventions.

To capture these secondary and tertiary deaths, researchers will need to use datasets from primary and secondary care. Comparisons must be made with previous years to calculate how covid-19 has affected access to surgery and palliative therapies. Mortality data before and after the pandemic will need to be compared to see if there has been a permanent effect, secondary to the reorganisation of healthcare services due to covid-19. Only when more expanded definitions of covid-19 related mortality are used will the true effect of the pandemic be known.

Competing interests: None declared.

Full response at: https://www.bmj.com/content/369/bmj.m1607/rr-3.

Appleby J. What is happening to non-covid deaths?BMJ 2020;369:m1607. 10.1136/bmj.m1607 32332059

Published by the BMJ Publishing Group Limited. For permission to use (where not already granted under a licence) please go to http://group.bmj.com/group/rights-licensing/ permissions 